\title{
Caregiver Burden Associated-Risk Factor of Chronic Kidney Disease Patients with Hemodialysis
}

\author{
Rahmat Alfi Syahri $^{1 *}$, Said Usman ${ }^{1,2}$, Irwan Saputra ${ }^{1,2}$, Hajjul Kamil $^{1,2}$, Nurjannah ${ }^{1,2}$ \\ ${ }^{I}$ Postgraduate program, Faculty of Medicine, Universitas Syiah Kuala \\ ${ }^{2}$ Departement of Community Medicine, Faculty of Medicine, Universitas Syiah Kuala \\ *alfi.alpi.alvi@gmail.com
}

\begin{abstract}
Caregiver of patients with hemodialysis is the crucial part for the continuation of management in chronic kidney disease (CKD). Therefore, evaluation and identification of several risk factors associated with its burden is mandatory. This study aimed to identify several risk factors related to the high caregiver burden (CB) of hemodialysis patients. The study was design cross-sectional and conducted in hemodialysis unit of Local Hospital of Zainal Abidin, Banda Aceh, Indonesia during January 2020. All respondents who were suitable for the inclusion criteria would automatically include into the study. Respondents must be a caregiver for one of his family members who underwent dialysis treatment in the center and signed informed consent for the study enrollment. Caregiver burden was assessed using standardized questionnaire based on Zarit Burden Scale and The Montgomery Borgotta Caregiver Burden Scale which consists of 39 questions. There were 40 respondents who included into the study with following results, the statistical analysis has been proved that significant relationship of gender and knowledge level was evident in the study with the high CB ( -value < 0.05) while age, education level, and treatment duration was not associated with $\mathrm{CB}$ in the study. The linkage between those risk factors must be considered in every circumstance for patient well-being since its relationship with higher CB was evident through the study.
\end{abstract}

Keywords: Burden, Caregiver, Risk Factor 


\section{STRADA Jurnal Ilmiah Kesehatan}

DOI: $10.30994 /$ sjik.v9i2.327

ISSN: 2252-3847 (print); 2614-350X (online)

Vol.9 No.2 November 2020 Page.481-487

\section{BACKGROUND}

Chronic kidney disease (CKD) is a terminal disease caused by the chronic process of kidney disease characterized by a decrease in glomerular filtration rate (LFG) (Webster et al., 2017). In definition, the diagnostic criteria for CKD include two criteria, including: (1) Kidney damage that occurs more than three months, either due to structural or functional abnormalities, with or without Glomerular Filtration Rate (GFR) reduction. This can be proven based on pathological examination, laboratory (blood or urine composition) or imaging studies, and (2) GFR is less than $60 \mathrm{ml} / \mathrm{min} / 1.73 \mathrm{~m}^{2}$ for three months (Levey et al., 2011). Furthermore, the Kidney Disease Outcomes Quality Initiative (KDOQI) divides CKD into five stages based on the actual glomerular filtration rate (GFR) (Ali et al., 2013). The progression of chronic renal failure is dependent on the number of damaged-nephron, which in turn causes progressive decline in kidney function as well as fall into end stage renal disease (ESRD) which urgently needs hemodialysis therapy (Isakova et al., 2017).

ESRD is a term for the last stage of CKD that it is unable to fulfill their physiological functions and thus require kidney replacement therapy, such as hemodialysis, peritoneal hemodialysis, or kidney transplantation (Akchurin and Kasker, 2015). Recently, CKD sufferers who performed hemodialysis were more than 3 million in 2012 and increased to 3.2 million in 2013 with an average growth of $6 \%$ based on data compiled from The United States Renal Data system (USRDS) (Foley and Collins, 2013). Meanwhile, Indonesia has a total of 22,304 CKD patients underwent hemodialysis in 2011 and grew larger become 28,782 patients in 2012 (Pernefri, 2012). In Indonesia, the tendency of hemodialysis management is related to age, prevalence of hemodialysis increased considerably in the age group of $35-44$ years by $0.3 \%$ followed by age $45-54$ years $(0.4 \%)$ and highest in the age group above 75 years $(0.6 \%)$ with gender predominance men are higher than women (Riskesdas, 2013).

Following this epidemiologic transition, there are several important components that play a major role in the process of successful management among CKD patients, one of which is the existence of caregiver (Tong et al., 2008). Caregiver is a person who provides direct care for children or adults who suffer from chronic diseases, based on the Merriam-Webster Dictionary (2012). Caregiver was also defined as individuals who have several tasks with helping people who are handicapped/disabled to perform daily physical activities (Streck et al., 2020). Caregiver or family caregiver in patients with CKD undergoing hemodialysis has five activities, including: assessing, advocating, entertaining, providing daily assistance, and providing training (Bayoumi, 2014). In addition, family caregiver also specifically regulates diet, nutrition, acknowledging treatments and symptoms, and treating them personally (Pereira et al., 2017). Caregiver is separated into two forms; it include formal, in the form of caregivers provided at the hospital, for instance; nurses, psychiatrists, or other medical personnel who receive rewards/ services in the form of salaries, while informal caregiver is caregivers who come from families, such as husband/ wife, father/ mother, child, brother/ sister, or other family members. The role of informal caregivers in Indonesia is significant due to cultural factors that firmly established in the community (Putri DP, 2014)

The implications of the ongoing treatment, hemodialysis, will put a burden on the Caregiver. Burden can be interpreted as a negative implication or influence, whether in several formulations of emotional, physical, social, or financial status that occurs due to the process of caring for someone with an impaired condition (Bastawrous, 2013). There 


\section{STRADA Jurnal Ilmiah Kesehatan}

DOI: $10.30994 /$ sjik.v9i2.327

ISSN: 2252-3847 (print); 2614-350X (online)

Vol.9 No.2 November 2020 Page.481-487

are several factors affecting Caregiver burden (CB), but the proximity of caregiver with the sufferers which is found positively correlated with caregiver burden. Theoretically, $\mathrm{CB}$ is defined as a multidimensional reaction as a result of the imbalance of care over personal time and social roles, physical and emotional state of financial resources, and social resources that will affect the overall caregiver's well-being and quality of life (Bainbridge et al., 2009). CB also deals with physical, psychological and social problems because there is no attention given to caregivers (Avsar et al., 2015).

An evaluation of the burden of caregiver needs to be performed in order to ensure the continuity of treatment as well as the assessment and identification of several factors related to the presence of $\mathrm{CB}$, including: access to information, knowledge of disease, age, and proximity (Sav et al., 2015). Therefore, this study aims to identify several factors associated with caregiver burden in families of patients with chronic kidney disease.

\section{METHODS \\ Study Design and Sample}

This research is an observational study using a cross-sectional design at the Hemodialysis Installation, Zainoel Abidin Regional General Hospital (RSUZA), Banda Aceh, Indonesia in March 2020. The study population was representative of family members who accompanied hemodialysis patients at the Installation RSUDZA by using accidental sampling technique (all samples that were present at the time of the survey if they met the inclusion criteria and signed an informed consent would automatically enroll into the study). The study inclusion criteria included: the study subjects were CKD patients undergoing regular hemodialysis for more than three months and the exclusion criteria were respondents who were uncooperative, unwilling, and unable to read and fill in the questionnaire.

\section{Caregiver Burden}

All variables are evaluated using standardized questionnaires. $\mathrm{CB}$ is an uncomfortable situation/ burden/ negative impact resulting from caring for disturbed family members, $\mathrm{CB}$ variables are evaluated using a questionnaire then divided into high and low CB. CB evaluation uses the caregiver burden assessment (CBA) adapted from Zarit Burden Scale and The Montgomery Borgotta Caregiver Burden Scale which consists of 39 questions to measure subjective burden as well as objective burden (Macedo et al., 2015). Age, gender, and educational level are the baseline characteristic of respondents included in the study based on the results of direct interviews. Meanwhile, the le was divided into three groups, firstly under one year, 1-3 years, and above 3 years. Then, knowledge level is divided based on the scores obtained from the results of the questionnaire, high (above 75\%) and low (below 56\%).

\section{Statistical Analysis and Ethical Approval}

All data were then analyzed using univariate and bivariate software using the chisquare test. The software used is SPSS (Statistical Package for Social Science) with significant result would be indicated by the p-value $<0.05$ then Ho is rejected and if the value of P-value> 0.05 then Ho is accepted. In addition, all research protocols have also been approved by the Health Research Ethics Commission, Faculty of Medicine, Syiah Kuala University, Banda Aceh with letter number 032/ EA/ FK-RSUDZA/ 2020. 


\section{STRADA Jurnal Ilmiah Kesehatan}

DOI: $10.30994 /$ sjik.v9i2.327

ISSN: 2252-3847 (print); 2614-350X (online)

Vol.9 No.2 November 2020 Page.481-487

\section{RESULT}

A total of 40 respondents representing each CKD patient undergoing hemodialysis participated in the study. All respondents have been also declared in accordance the inclusion criteria and signed an informed consent. The demographic characteristics of the study respondents are depicted in Table 1. Descriptively, female still dominates the caregiver in this study, accompanied by more people tends to be caregivers as the age group younger. Almost a half of respondents also have a close proximity with patients, in this case 'children' as the first degree of family relations followed by husband/ wife and siblings. An evaluation of knowledge level using a questionnaire found that most caregivers lacked sufficient or low knowledge, as much as $60 \%$. Meanwhile, the results of bivariate analysis using chi-square found a significant relationship $(\mathrm{p}<0.05)$ between sex as well as knowledge level with caregiver burden (CB) while age, level of education, and length of stay were not significantly related to high $\mathrm{CB}$ based on statistical analysis.

Table 1. Demographic characteristics in the study

\begin{tabular}{ll}
\hline Characteristics & $\mathbf{n}(\%)$ \\
\hline Gender & $9(22.5)$ \\
Male & $31(77.5)$ \\
Female & $12(30.0)$ \\
\hline Age group (Years) & $12(30.0)$ \\
$17-25$ & $5(12.5)$ \\
$26-35$ & $9(22.5)$ \\
$36-45$ & $1(2.5)$ \\
$46-55$ & $1(2.5)$ \\
$56-65$ & $25(62.5)$ \\
$>65$ & $15(37.5)$ \\
\hline Marrital status & \\
Married & $25(62.5)$ \\
Unmarried & $15(37.5)$ \\
Job status & \\
Employed & $19(47.5)$ \\
Unemployed & $16(40.0)$ \\
Relations to patient & $2(5.0)$ \\
Child & $3(7.5)$ \\
Husband/Wife & $24(60.0)$ \\
Sister & $16(40.0)$ \\
Others & \\
Salary & \\
Low & \\
High & \\
\hline
\end{tabular}

Table 2. Bivariate analysis of several variables included in the study

\begin{tabular}{llll}
\hline \multicolumn{1}{c}{ Characteristics } & \multicolumn{2}{c}{ Caregiver Burden n (\%) } & p-value \\
\cline { 2 - 3 } & \multicolumn{2}{c}{ Low } & \multicolumn{2}{c}{ High } \\
\hline Gender & \multicolumn{3}{c}{$0.005^{*}$} \\
Male & $1(11.1)$ & $8(88.9)$ & \\
Female & $20(64.5)$ & $11(35.5)$ & \\
\hline
\end{tabular}

Website: https://sjik.org/index.php/sjik | Email: publikasistrada@gmail.com 


\section{STRADA Jurnal Ilmiah Kesehatan}

DOI: $10.30994 /$ sjik.v9i2.327

\begin{tabular}{llll}
\hline Age (year) & & & \\
$17-25$ & $10(83.3)$ & $2(16.7)$ & 0.103 \\
$26-35$ & $6(50.0)$ & $6(50.0)$ & \\
$36-45$ & $1(20.0)$ & $4(80.0)$ & \\
$46-55$ & $4(44.4)$ & $5(55.6)$ & \\
$56-65$ & $0(0.0)$ & $1(100.0)$ & \\
$>65$ & $0(0.0)$ & $1(100.0)$ & \\
\hline Education level & & & \\
University & $14(50.0)$ & $14(50.0)$ & 0.609 \\
Senior High & $6(54.5)$ & $5(45.5)$ & \\
Junior High & $1(100)$ & $0(0.0)$ & \\
Treatment duration & & & \\
(year) & $8(61.5)$ & $5(38.5)$ & 0.282 \\
$<1$ & $9(60.0)$ & $6(40.0)$ & \\
$1-3$ year & $4(33.3)$ & $8(66.7)$ & \\
$>3$ year & & & \\
\hline Education level & & $13(72.2)$ & $0.005^{*}$ \\
Low & $5(27.8)$ & $6(27.3)$ & \\
High & $16(72.7)$ & $19(47.5)$ & \\
\hline Total & $21(52.5)$ &
\end{tabular}

\section{DISCUSSION}

This study demonstrates a significant relationship between gender and knowledge level of CKD with high $\mathrm{CB}$. This indicates that the relationship between two variables follow causal-effect principle. Based on gender, most of respondents were female and it had a significant relationship to CB. Based on recent findings, Mashayekhi et al. (2015) discovered that the majority of research subjects who are caregivers $(68.6 \%)$ were female. This is related to social participation which involves women in the care of family members and others (Ghosh and Greenberg, 2012). Meanwhile, knowledge level was also successfully proven by statistics related to high $\mathrm{CB}$, descriptive analysis also revealed this variable related to the incidence of caregivers who had high $\mathrm{CB}$ in the group of respondents who had low knowledge level of the disease; in fact, more than $50 \%$ of respondents who had low knowledge levels would have high CB. These results also in accordance to Mollagulu et al. (2013) who reported that higher knowledge level would be associated with lower CB scores.

Based on the age characteristics, the age group with the largest number of respondents was found in the 17-25 years and 26-35 years age groups. Age is the main determinant affecting the incidence of CB in other studies (Kim et al., 2012). Nevertheless insignificant analysis, higher CB distribution occurred at the age of more than 35 year age groups. Descriptively, the study also found there were differences in caregivers who had a low CB in caregivers with younger age groups but were unable to find a significant relationship between variables. Adelman (2014) also found that the increase in age of caregivers also linearly correlated with the increase in $\mathrm{CB}$ during the period of patient care. Another variable, education level, failed to show a significant relationship to $\mathrm{CB}$; however, the number of respondents were similar in each group (low vs high); therefore, the analysis did not succeed in obtaining a significant value. One study found that educational level of caregiver would make them having preparedness 


\section{STRADA Jurnal Ilmiah Kesehatan}

DOI: $10.30994 /$ sjik.v9i2.327

ISSN: 2252-3847 (print); 2614-350X (online)

Vol.9 No.2 November 2020 Page.481-487

for support and overcome problems or coping mechanism (Kate et al., 2013).

Treatment duration also did not have significant relationship with $\mathrm{CB}$ among respondents but it descriptively can be seen that treatment duration, more than three years, is highly associated with the high CB; it is discovered that more than $60 \%$ of respondents in this group has high $\mathrm{CB}$ but the change between treatment groups is indeed not proved linearly. Putri (2014) states that the patients which have underwent hemodialysis longer, the level of CB would alleviated in line with the maturity process of coping mechanism among patients and members of family resulting in burden attenuation (Cantekin et al., 2016; Geriani et al., 2015).

\section{CONCLUSIONS}

This study has discovered significant findings associated with caregiver burdens of chronic kidney disease patients with hemodialysis in the center. There must be a preventive measurement to prevent overwhelming burden ensue among caregiver, particularly of the caregiver who has several contributing factors for the occurrence of high CB.

\section{REFERENCES}

Adelman RD, Tmanova LL, Delgado D, Dion S, Lachs MS. (2014). Caregiver burden: A clinical review. JAMA - J Am Med Assoc, 311(10):1052-9.

Akchurin, M., \& Kaskel, F. (2015). Update on inflammation in chronic kidney disease. Blood purification, 39(1-3), 84-92.

Ali, A., Asif, N., \& Rais, Z. (2013). Estimation of GFR by MDRD formula and its correlation to Cockcroft-gault equation in five stages of chronic kidney disease.

Avşar, U., Avşar, U. Z., Cansever, Z., Yucel, A., Cankaya, E., Certez, H., ... \& Yucelf, N. (2015). Caregiver burden, anxiety, depression, and sleep quality differences in caregivers of hemodialysis patients compared with renal transplant patients. In Transplantation proceedings (Vol. 47, No. 5, pp. 1388-1391). Elsevier.

Bainbridge, D., Krueger, P., Lohfeld, L., \& Brazil, K. (2009). Stress processes in caring for an end-of-life family member: Application of a theoretical model. Aging \& Mental Health, 13(4), 537-545.

Bastawrous, M. (2013). Caregiver burden-A critical discussion. International journal of nursing studies, 50(3), 431-441.

Bayoumi, M. M. (2014). Subjective burden on family carers of hemodialysis patients. Open Journal of Nephrology.

Cantekin I, Kavurmaci M, Tan M. (2016). An analysis of caregiver burden of patients with hemodialysis and peritoneal dialysis. Hemodialysis International, 20(1), 94-7.

Foley, R. N., \& Collins, A. J. (2013). The USRDS: what you need to know about what it can and can't tell us about ESRD. Clinical journal of the American Society of Nephrology, 8(5), 845-851.

Geriani, D., Savithry, K. S. B., Shivakumar, S., \& Kanchan, T. (2015). Burden of care on caregivers of schizophrenia patients: a correlation to personality and coping. Journal of clinical and diagnostic research: JCDR, 9(3), VC01.

Ghosh, S., \& Greenberg, J. S. (2012). Gender difference in caregiving experience and the importance of social participation and marital satisfaction among aging mothers and fathers of adults with schizophrenia. Social Work in Mental Health, 10(2), 146-168. 


\section{STRADA Jurnal Ilmiah Kesehatan}

DOI: $10.30994 /$ sjik.v9i2.327

ISSN: 2252-3847 (print); 2614-350X (online)

Vol.9 No.2 November 2020 Page.481-487

Isakova, T., Nickolas, T. L., Denburg, M., Yarlagadda, S., Weiner, D. E., Gutiérrez, O. M., ... \& Kramer, H. (2017). KDOQI US commentary on the 2017 KDIGO clinical practice guideline update for the diagnosis, evaluation, prevention, and treatment of chronic kidney disease-mineral and bone disorder (CKD-MBD). American Journal of Kidney Diseases, 70(6), 737-751.

Kate, N., Grover, S., Kulhara, P., \& Nehra, R. (2013). Relationship of caregiver burden with coping strategies, social support, psychological morbidity, and quality of life in the caregivers of schizophrenia. Asian journal of psychiatry, 6(5), 380-388.

Kementrian Kesehatan RI. 2013. Riset Kesehatan Dasar. Jakarta: Kementrian Kesehatan RI.

Kim, H., Chang, M., Rose, K., \& Kim, S. (2012). Predictors of caregiver burden in caregivers of individuals with dementia. Journal of advanced nursing, 68(4), 846855.

Levey, A. S., De Jong, P. E., Coresh, J., Nahas, M. E., Astor, B. C., Matsushita, K., ... \& Eckardt, K. U. (2011). The definition, classification, and prognosis of chronic kidney disease: a KDIGO Controversies Conference report. Kidney international, 80(1), 17-28.

Macedo, E. C., Silva, L. R. D., Paiva, M. S., \& Ramos, M. N. P. (2015). Burden and quality of life of mothers of children and adolescents with chronic illnesses: an integrative review. Revista latino-americana de enfermagem, 23(4), 769-777.

Mashayekhi F, Pilevarzadeh M, Rafati F. (2015). The Assessment of Caregiver Burden in Caregivers of Hemodialysis Patients. Mater Socio Medica, 27(5), 333

Mollaoğlu, M., Kayataş, M., \& Yürügen, B. (2013). Effects on caregiver burden of education related to home care in patients undergoing hemodialysis. Hemodialysis International, 17(3), 413-420.

Pereira, B., da Silva Fernandes, N., de Melo, N. P., Abrita, R., dos Santos Grincenkov, F. R., \& da Silva Fernandes, N. M. (2017). Beyond quality of life: a cross sectional study on the mental health of patients with chronic kidney disease undergoing dialysis and their caregivers. Health and quality of life outcomes, 15(1), 74.

PERNEEFRI. (2012). 5th Report Of Indonesian Renal Registry. Jakarta: Perhimpunan Nefrologi Indonesia.

Putri DP, Konginan A, Mardiana N. (2014). Korelasi Social Support Dengan Caregiver Burden Yang Menjalani Hemodialisis Di RSUD Dr Soetomo Surabaya.

Sav, A., King, M. A., Whitty, J. A., Kendall, E., McMillan, S. S., Kelly, F., ... \& Wheeler, A. J. (2015). Burden of treatment for chronic illness: a concept analysis and review of the literature. Health Expectations, 18(3), 312-324.

Streck, B. P., Wardell, D. W., \& Wood, G. L. (2020). Family Caregiver-Receiver Mutuality: A Concept Analysis. Advances in Nursing Science, 43(2), E71-E79.

Tong, A., Sainsbury, P., \& Craig, J. C. (2008). Support interventions for caregivers of people with chronic kidney disease: a systematic review. Nephrology Dialysis Transplantation, 23(12), 3960-3965.

Webster, A. C., Nagler, E. V., Morton, R. L., \& Masson, P. (2017). Chronic kidney disease. The lancet, 389(10075), 1238-1252 